\title{
LÍNGUAS AFRICANAS NO PORTUGUÊS BRASILEIRO
}

\author{
Calundu - Grupo de Estudos sobre Religiões Afro-Brasileiras ${ }^{1}$
}

DOI: $10.26512 /$ revistacalundu.v3i1.25243

A história desse país traz as marcas da escravidão. Primeiro, os povos indígenas, que aqui habitavam foram dizimados pelos portugueses. Em seguida, durante quatro séculos, milhões ${ }^{2}$ de africanos foram trazidos em cativeiro para serem escravizados no Brasil. Inicialmente, chegaram os africanos do mesmo grupo etnolinguístico - os bantos $^{3}$, que se dispersaram pelos estados do Rio de Janeiro e Pernambuco. Posteriormente, os africanos da região sudanesa ${ }^{4}$ (do Senegal à Nigéria) chegaram à Bahia.

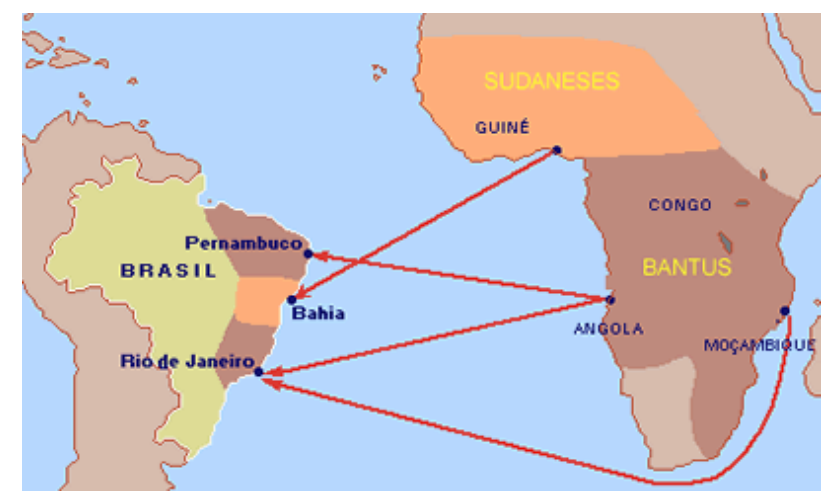

Figura 1 - Mapa do tráfico transatlântico de africanos escravizados para o Brasil. Silva (2014)

\footnotetext{
${ }^{1}$ Texto de autoria coletiva elaborado para o projeto de extensão "Diálogos Comunitários Calunduzeiros". Fazem parte do projeto, em ordem alfabética: Adélia Regina da Silva Mathias, Aisha Angèle Leandro Diéne, Andréa Letícia Carvalho Guimarães, Ariadne Moreira Basílio, Clara Jane Costa Adad, Danielle de Cássia Afonso Ramos, Francisco Phelipe Cunha Paz, Gerlaine Torres Martini, Guilherme Dantas Nogueira, Hans Carrillo Guach, Iyaromi Feitosa Ahualli, Luís Augusto Ferreira Saraiva, Nathalia Vince Esgalha Fernandes, Tania Mara Campos de Almeida.

2 Anexo - Número de escravos que entraram no Brasil entre os séculos XVI e XIX.

3 “A região banto compreende um" grupo de 300 línguas muito semelhantes, faladas em 21 países: Camarões, Chade, República Centro-Africana, Guiné Equatorial, Gabão, Angola, Namíbia, República Popular do Congo (Congo-Brazzaville), República Democrática do Congo (RDC ou Congo-Kinshasa), Burundi, Ruanda,

"Uganda, Tanzânia, Quênia, Malavi, Zâmbia, Zimbábue, Botsuana, Lesoto, Moçambique, África do Sul". (CASTRO, 2005, p. 3).

4 “As línguas oeste-africanas, chamadas de sudanesas, as mais importantes foram as línguas da família kwa, faladas no Golfo do Benin". Seus principais representantes no Brasil foram os iorubas, os povos de línguas do grupo ewe-fon que foram apelidados pelo tráfico de minas ou jejes. O ioruba é uma língua única, constituída por um grupo de falares regionais concentrados no sudoeste da Nigéria (ijexá, oió, ifé, ondô, etc.) e no antigo Reino de Queto (Ketu), hoje no Benim, onde é chamada de nagô, denominação pela qual os iorubas ficaram tradicionalmente conhecidos no Brasil. Já o ewe-fon é um conjunto de línguas (mina, ewe, gun, fon, mahi) muito parecidas e faladas em territórios de Gana, Togo e Benim. "Entre elas a língua fon, numericamente majoritária na região, é falada pelos fons ou daomeanos, concentrados geograficamente no planalto central de Abomé, capital do antigo Reino do Daomé, no Benim atual". (CASTRO, 2005, p.3).
} 
Importante salientar que os colonizadores, na tentativa de enfraquecer os laços familiares e esvaziar a resistência dos negros, separaram os grupos provenientes da mesma região dificultando a comunicação entre eles. No entanto, a influência das línguas bantas foi considerada proeminente.

\begin{abstract}
Nesse processo, o negro banto, pela antiguidade, volume populacional e amplitude territorial alcançada pela sua presença no Brasil colônia, como os outros, adquiriu o português como segunda língua, tornandose o principal agente transformador da língua portuguesa em sua modalidade brasileira e seu difusor pelo território brasileiro sobregime colonial e escravista. [...] Ao encontro dessa matriz já estabelecida, assentaram-se os aportes do ewe-fon e do iorubá, menos extensos e mais localizados, embora igualmente significativos para o processo de síntese pluricultural brasileira, sobretudo no domínio da religião. (CASTRO, 2005, p.8)
\end{abstract}

Mas o que o tráfico de africanos escravizados tem a ver com o português brasileiro? Tudo. E é por isso que o português brasileiro é tão diferente do português europeu. Infelizmente, o que ocorre é a invisibilidade das contribuições desses povos africanos causada, principalmente, pelo preconceito.

Os pioneiros a considerar a importância do africanismo no português do Brasil foram Renato Firmino Maia de Mendonça na década de $30 \mathrm{com}$ A Influência Africana no Português do Brasil, publicada sucessivamente em 1933, 1935, 1948 e republicada em 1972 e 1973; e Jacques Raimundo que em 1933 divulgou O Elemento Afro-Negro na Língua Portuguesa.

Lélia Gonzalez (1988, p.70), quando escreveu A Categoria Político-Cultural de Amefricanidade, cunhou o termo pretoguês para nominar "a marca de africanização do português falado no Brasil (nunca esquecendo que o colonizador chamava os escravos africanos de 'pretos' e de 'crioulos' os nascidos no Brasil)".

Yeda Castro (2005, p.8) em A Influência das Línguas Africanas no Português Brasileiro salienta a relevância do contato direto e permanente entre africanos e a língua brasileira. "Português do Brasil, naquilo em que ele se afastou do português de Portugal, descontada a matriz indígena menos extensa e mais localizada, é, em grande parte, o resultado de um movimento implícito de africanização do português".

Maria do Socorro S. de Aragão (2011) em Africanismos no Português do Brasil destaca a influência dos contextos socioculturais (valores, costumes, tradições, religião) na língua. 
Não se pode estudar a língua sem relacioná-la com a sociedade e a cultura nas quais o falante está inserido. No caso dos africanismos incorporados à língua portuguesa do Brasil, os costumes, as tradições, as comidas, as músicas trazidas pelos negros escravos foram determinantes não apenas no aspecto léxico, mas também no aspecto fonético-fonológico. (ARAGÃO, 2011, p.9).

Marcos Bagno (2016) se manifestou sobre o tema em O Impacto das Línguas Bantas na Formação do Português Brasileiro atribuindo ao racismo a demora pelo reconhecimento das contribuições africanas ao idioma nacional.

Durante muitas e muitas décadas, o impacto dos falantes de origem africana sobre a formação do português brasileiro foi ou simplesmente negado ou reduzido a aspectos caricaturais, como as recorrentes listas de palavras de origem africana introduzidas na nossa língua. Só muito recentemente, menos de trinta anos na verdade, é que um novo impulso de pesquisa tem lançado luzes cada vez mais fortes sobre o que podemos agora chamar sem rodeios de origens africanas do português brasileiro ou, como sugere o título de um livro importante sobre o assunto, o português afro-brasileiro (Lucchesi, Baxter e Ribeiro, 2009). Cada vez mais autores reconhecem que as diferenças marcantes entre o português brasileiro e a língua da qual ele se originou - o português europeu em sua fase de transição do período medieval para o moderno - se devem primordialmente ao multilinguismo que caracterizou a história do Brasil na maior parte do período colonial. A dispersão pelo território brasileiro de milhões de negros escravizados, falantes de muitas línguas diferentes, não pode ter deixado de incidir fortemente sobre o desenvolvimento do português brasileiro. (BAGNO, 2016, p.20)

De acordo com Castro (op. cit., p.8) é provável que a interação linguística tivesse sido viabilizada "pela proximidade relativa da estrutura linguística do português europeu antigo e regional com as línguas negro-africanas". Dentre elas a presença das "vogais orais (a, e, ê, é i, o, u) e a estrutura silábica ideal (CV. CV) (consoante vogal. consoante vogal)". Outra contribuição marcante é na fonologia (pronúncia).

A tendência do falante brasileiro em omitir as consoantes finais das palavras ou transformá-las em vogais, (falá, dizê, Brasiu), coincide com a estrutura silábica das palavras em banto e em iorubá, que nunca terminam em consoante. Ainda de acordo com a estrutura silábica dessas línguas, onde não existem encontros consonantais, como ocorre em português, também se observa, na linguagem popular brasileira, a tendência de desfazer esse tipo de encontro, seja na mesma sílaba ou em sílabas contíguas, pela intromissão de uma vogal entre elas, que termina por produzir outra sílaba, a exemplo de 'saravá para salvar e 
Revista Calundu - Vol.3, N.1, Jan-Jun 2019

fulô para flor'. (CASTRO, 2005, p.10-11)

Vale destacar que as palavras de origem africana situam-se principalmente na fala e menos na escrita; e durante as comunicações diretas. Essa constatação vai ao encontro de outra característica marcante dos povos africanos: a oralidade. Exemplos: camundongo, caxumba, cafuné, dengo, paparicar, cachaça, moqueca, fuzuê, cabaço, mano, catinga, etc.

Historicamente, as contribuições africanas foram preconceituosamente recusadas. Um dos fatores é que a história do Brasil foi escrita e contada pelas lentes dos colonizadores - europeus brancos - que usurparam povos africanos de sua terra natal e impediram que eles contassem suas histórias. É indispensável reconhecer essas contribuições como substanciais e importantes na formação não só do português brasileiro, mas da identidade nacional.

\section{Referências Bibliográficas}

ARAGÃO, Maria do Socorro S. "Africanismos no Português do Brasil". Revista de Letras (Fortaleza), v.30, p. 07-16, 2011.

BAGNO, Marcos. "O impacto das línguas bantas na formação do português brasileiro". Cadernos de Literatura em Tradução, Brasil, n. 16, maio 2016. ISSN 2359-5388. Disponível em: <http://www.revistas.usp.br/clt/article/view/115266>. Acesso em: 15 junhos 2018.

BARROS, Rachel R. de A.; CAVALCANTI, B. C. "O lugar social das palavras africanas no português do Brasil". In: BARROS, Rachel R. de A.; CAVALCANTI, B. C.; FERNANDES, Clara S. (Org.). Kulé Kulé - Visibilidades negras. 1ªd.Maceió: EDUFAL, 2006, v. , p. 9-13.

CASTRO, Yeda Pessoa. A influência das línguas africanas no português brasileiro. In: Secretaria Municipal de Educação - Prefeitura da Cidade de Salvador (org.). Salvador: Secretaria Municipal de Educação, 2005.

GONZALEZ, Lélia. "A categoria político-cultural de amefricanidade". In: Tempo Brasileiro. Rio de Janeiro, n. 92/93(jan/jun), p. 69-82, 1988.

MENDONÇA, Renato. A influência africana no português do Brasil. $2^{\mathrm{a}}$ ed. São Paulo: Editora Nacional, $1935 . \quad$ Disponível em: <http://www.brasiliana.com.br/brasiliana/colecao/obras/314/a-influencia-africana-noportugues-do-brasil>. Acesso em: 18 de junho de 2018. 
Revista Calundu - Vol.3, N.1, Jan-Jun 2019

\section{ANEXO}

Número de escravos que entraram no Brasil entre os séculos XVI e XIX.

Número de escravos entrados no Brasil

(avaliação baseada em estatísticas aduaneiras subsistentes)

\begin{tabular}{|c|c|c|c|c|}
\hline & Regiōes & $\begin{array}{c}\text { Entradas } \\
\text { anuais }\end{array}$ & $\begin{array}{l}\text { Total } \\
\text { ânuo }\end{array}$ & $\begin{array}{l}\text { Total da } \\
\text { importação }\end{array}$ \\
\hline $\begin{array}{c}\text { Seculo } \\
\text { XVI }\end{array}$ & Todo o Brasil . . : & $\cdots \cdots$ & $\ldots \ldots$ & 30.000 \\
\hline $\begin{array}{l}\text { Século } \\
\text { XVII }\end{array}$ & $\begin{array}{l}\text { Brasil holandês. . } \\
\text { Brasil português . . }\end{array}$ & $\begin{array}{l}3.000 \\
5.000\end{array}$ & 8.000 & 800.000 \\
\hline $\begin{array}{l}\text { Século } \\
\text { XVIII }\end{array}$ & $\begin{array}{l}\text { Pará. . . . . . . } \\
\text { Recife. . . . . . } \\
\text { Baía . . . . . } \\
\text { Rio. . . . . . . }\end{array}$ & $\begin{array}{r}600 \\
5.000 \\
8.000 \\
12.000\end{array}$ & 25.000 & 2.500 .000 \\
\hline $\begin{array}{l}\text { Século } \\
\text { XIX } \\
\text { (ate 1830) }\end{array}$ & $\begin{array}{l}\text { Rio. . . . . } \\
\text { Todo o Brasil . . . }\end{array}$ & $\begin{array}{l}20.000 \\
\ldots\end{array}$ & 50.000 & 1. 500.000 \\
\hline Durant & tráfico . . . . . & . . & . & 4.830 .000 \\
\hline
\end{tabular}

Fonte: Mendonça, 1935, p.71.

Recebido em: 05/05/2019

Aceito em: 13/05/2019 